\title{
The association between number of doctors per bed and readmission of elderly patients with pneumonia in South Korea
}

\author{
Joo Eun Lee ${ }^{1,2}$, Tae Hyun Kim ${ }^{2,3}$, Kyoung Hee Cho ${ }^{1,2}$, Kyu-Tae Han ${ }^{1,2}$ and Eun-Cheol Park ${ }^{2, *^{*}}$
}

\begin{abstract}
Background: There is an urgent need to reduce readmission of patients with pneumonia and improve quality of care. To assess the association between hospital resources and quality of care, we examined the effect of number of doctors per bed on 30-day readmission and investigated the combined effect of number of doctors per bed and number of beds.

Methods: We used nationwide cohort sample data of health insurance claims by the National Health Insurance Service (NHIS) from 2002 to 2013. Pneumonia admissions to acute care hospitals among 7446 inpatients older than 65 were examined. We conducted a multivariate Cox proportional hazard model to analyze the association between the number of doctors per bed and 30-day readmission, as well as that of pneumonia-specific 30-day readmission with the combined effects of number of doctors per bed and number of beds.

Results: Overall, 1421 (19.1\%) patients were readmitted within 30 days and 756 (11.2\%) patients were readmitted for pneumonia within 30 days. Patients with pneumonia treated by very low or low number of doctors per bed showed higher readmission (pneumonia-specific readmission: hazard ratio $[H R]=1.406,95 \%$ confidence interval $[\mathrm{Cl}]=1.072-1.843$ for low number of doctors per bed; all-cause readmissions: $\mathrm{HR}=1.276,95 \% \mathrm{Cl}=1.026-1.587$ for very low number of doctors per bed, and $\mathrm{HR}=1.280,95 \% \mathrm{Cl}=1.064-1.540$ for low number of doctors per bed).

Conclusions: This empirical study showed that patients with pneumonia cared for in hospitals with more doctors were less likely to be readmitted. Pneumonia-specific 30-day readmission was also significantly associated with the combined effect of the number of doctors and the number of hospital beds.
\end{abstract}

Keywords: Readmission, Pneumonia, Number of doctors per bed

\section{Background}

Pneumonia is more common in older individuals and remains as the leading cause of death among the elderly worldwide. Older patients with pneumonia experience longer hospital stays and more comorbidities than young adults [1]. According to 2013 Statistics Korea data, pneumonia has risen from the twelfth to the sixth leading cause of death, with the death rate increasing from 5.7 to 21.4 per 100,000 over the past 10 years [2]. In

\footnotetext{
* Correspondence: ecpark@yuhs.ac

${ }^{2}$ Institute of Health Services Research, Yonsei University College of Medicine, Seoul, Republic of Korea

${ }^{4}$ Department of Preventive Medicine, Yonsei University College of Medicine, 50 Yonsei-ro, Seodaemun-gu, Seoul 120-752, Republic of Korea

Full list of author information is available at the end of the article
}

addition, pneumonia has the highest rate of admission among people aged over 50 and there were 232,000 pneumonia inpatients in 2013 [2]. Low birth rate and the rapidly aging population are major reasons for the increase in pneumonia in South Korea. Pneumonia patients older than 65 cost 6.7 -fold more than those aged 15 to 44 , and $75 \%$ of associated medical expenses are reported to be for hospital admission in Korea [3].

Pneumonia is a common reason for readmission after discharge and pneumonia patients are especially vulnerable to readmission $[4,5]$. Readmission due to pneumonia after discharge is also related to increased medical expenses and mortality [6]. Hospital readmissions are an indicator of poor health care quality [7-10]. According 
to a 2009 meta-analysis, urgent readmissions were often classified as avoidable, with the most commonly used investigation period being 30 days after discharge [11]. In South Korea, readmission rates for pneumonia and the seven diagnosis-related groups are indicators used to evaluate hospital programs. Similarly, the U.S. Centers for Medicare \& Medicaid Services (CMS) publicly report 30-day hospital-wide readmission rates for acute myocardial infarction (AMI), heart failure, pneumonia, Chronic Obstructive Pulmonary Disease (COPD), stroke, and hip/knee arthroplasty [12]. CMS identified hospital avoidable readmissions as a major reason for excessive medical costs and has tried to reduce avoidable readmission to improve quality of care and decrease unnecessary medical expenses [13].

Human resources in hospital, especially the number of doctors, may affect healthcare outcomes [14]. In addition, the demand for health care has increased in Korea. Nevertheless, the number of doctors in South Korea (2.2 doctors per 1000) is still lower than the Organization for Economic Cooperation and Development (OECD) average (3.3 doctors per 1000) [15]. This imbalance may affect negatively patient outcomes including readmission. Therefore, this study focused on the number of doctors per bed and pneumonia readmission to examine the association between professional human resource and patient outcomes.

To our knowledge, most readmission studies have focused on patient demographic and disease-specific factors and have analyzed all-cause readmission as the study outcome without using nationwide data [16-19]. Readmission may be affected by both patient and hospital factors [20]. Although pneumonia is a common reason for readmission which is related to poor health care quality, few Korean studies on readmission risk factors have assessed nationwide data, especially for pneumonia-specific readmission [9]. We aimed to identify the effect of patient and hospital characteristics on 30-day pneumonia-specific readmission to assess quality of care using a nationwide sample of cohort clinical data. This study hypothesized that characteristics affecting pneumonia-related readmission would be different from those of pneumonia-unrelated readmission.

\section{Methods}

\section{Data source and study sample}

A retrospective cohort study was performed using National Health Insurance Service (NHIS) claims from 2002 to 2013. NHIS covers all Korean citizens, as it requires mandatory enrollment. The NHIS sample data includes about 1 million people as a representative sample of the Korean population. We retrospectively reviewed health insurance claims of patients older than 65 years who were hospitalized with pneumonia between 2003 and 2013. Several inclusion criteria were considered to select the study sample. First, only patients over 65 years were selected because the characteristics of pneumonia are different in younger individuals. Second, we included inpatients who were diagnosed with pneumonia via the principal diagnosis (except clinics or physician offices and long-term care hospitals). Third, to consider prior health care utilization, we used data starting from the second year (2003). Finally, after excluding the missing data, we identified 7446 pneumonia patients who met these criteria. The number of hospitals included in this study sample was 1223.

\section{Ethics}

This study was approved by the Institutional Review Board of Graduate School of Public Health in Yonsei University for using data and study design (2014-202). And, this study was not included informed consents from the patients, because the patient's information had been already anonymized and de-identified prior to analysis.

\section{Outcome measures}

Our primary outcome variable was readmission within 30 days of hospital discharge from pneumonia. Discharge and readmission dates were obtained from medical statements. Readmission was classified as pneumonia-related, pneumonia-unrelated, and all-cause readmission. In the current study, readmission was defined as pneumoniarelated readmission if pneumonia was the primary diagnosis for readmission. Readmission was classified as pneumonia-unrelated readmission if patients were readmitted for alternative medical problems. All-cause readmission was defined as readmission for any cause after discharge from pneumonia.

\section{Independent variable}

The interesting variable in this study was the number of doctors per bed. The number of doctors per bed was calculated based on the total number of doctors and number of beds in each hospital. Then, we grouped the number of doctors per bed into quartiles (very low, low, high, or very high).

\section{Covariates}

According to our literature review and NHIS data availability, we used covariates of four categories: (1) demographic and socioeconomic variables: sex, age, and income level; (2) prior health care utilization: length of stay (LOS) in last year, number of outpatient visits in the last year, number of emergency visits in the last year, and charges in last year, LOS of index hospitalization; (3) risk and comorbidity: admission pathway, septicemia/shock, cancer, dementia, heart failure, vascular or 
circulatory disease, chronic obstructive pulmonary disease (COPD), asthma, renal failure, and liver disease; (4) hospital characteristics: hospital classification, ownership, number of beds, and availability of magnetic resonance imaging (MRI).

\section{Analytical approach}

Continuous variables were described as means and standard deviations and categorical variables were described as frequencies and percents. $x^{2}$ and $t$-tests were performed to evaluate differences in characteristics according to readmission. Kaplan-Meier survival curves were constructed for the number of doctors per bed and comparisons were made using log-rank tests. We used Cox proportional hazard frailty models using random effect at hospital level to examine the effect of patient and hospital characteristics on 30-day readmission for pneumonia. SAS 9.4 software (SAS Institute Inc., Cary, NC) was used for all analyses.

\section{Results}

\section{Patient and hospital characteristics}

The descriptive statistics stratified by 30-day pneumoniaspecific readmission, 30-day pneumonia-unrelated readmission, and 30-day all-cause readmission are shown in Table 1. In total, 7446 subjects were analyzed. Of all patients hospitalized with pneumonia between 2003 and 2013, 756 (11.2\%) were readmitted for pneumonia within 30 days numbered, 665 (9.9\%) for other medical problems within 30 days, and 1421 (19.1\%) for all causes within 30 days were. The average health care utilization in the prior year was higher in readmission groups than those not readmitted. Patients readmitted for pneumonia within 30 days had higher proportions of septicemia/shock, vascular or circulatory disease, COPD, asthma, and liver disease compared to those not readmitted. On the other hand, the patients readmitted for other medical problems or all causes within 30 days showed higher proportions of septicemia/shock, cancer, heart failure, vascular or circulatory disease, COPD, asthma, renal failure, and liver disease than those who were not readmitted.

Hospital-level characteristics according to readmission among inpatients with pneumonia are shown in Table 1. Among patients hospitalized with pneumonia, those admitted to hospitals with higher number of beds were less likely to be readmitted for pneumonia or all-cause than those admitted to smaller hospitals. Patients admitted to hospitals with higher number of doctors per bed were also less likely to be experience pneumonia-specific or all-cause readmissions.

\section{Kaplan-Meier curves of 30-day readmissions for pneumonia according to number of doctors per bed} Kaplan-Meier curves of 30-day pneumonia-specific, pneumonia-unrelated, and all-cause readmissions according to the number of doctors per bed (Q1, Q2, Q3, and Q4) showed differences. This study defined six groups of pneumonia patients: (1) 30-day pneumonia-specific readmissions by the number of doctors per bed $(13.5 \%$ readmission rate for Q1, 13.2\% readmission rate for Q2, 8.97\% readmission rate for $\mathrm{Q} 3$, and $8.04 \%$ readmission rate for $\mathrm{Q} 4)$, (2) 30-day pneumonia-unrelated readmissions by the number of doctors per bed (9.81\% readmission rate for Q1, 9.47\% readmission rate for Q2, 9.65\% readmission rate for Q3, and $10.81 \%$ readmission rate for $\mathrm{Q} 4$ ),, (3) 30-day all-cause readmissions by the number of doctors per bed $(20.72 \%$ readmission rate for Q1, 20.71\% readmission rate for Q2, $17.03 \%$ readmission rate for Q3, and $17.26 \%$ readmission rate for Q4), (Fig. 1). The log-rank test detected significant differences between very low, low, high and very high number of doctors per 100 beds for pneumonia-specific and allcause readmissions $(p<0.0001$ and $p=0.003)$, but not for pneumonia-unrelated readmission $(p=0.2491)$.

\section{Cox proportional hazard models of 30-day readmissions for pneumonia}

In the multivariable analysis, the number of doctors per bed was significantly associated with pneumonia-specific, and all-cause readmissions (pneumonia-specific readmission: hazard ratio $[\mathrm{HR}]=1.406,95 \%$ confidence interval $[\mathrm{CI}]=1.072-1.843$ for $\mathrm{Q} 2$; all-cause readmissions: $\mathrm{HR}=1.276,95 \% \mathrm{CI}=1.026-1.587$ for $\mathrm{Q} 1$, and $\mathrm{HR}=1.280$, $95 \% \mathrm{CI}=1.064-1.540$ for Q2) (Table 2). LOS in the prior year showed a negative association with pneumoniaspecific readmission $(\mathrm{HR}=0.836,95 \% \mathrm{CI}=0.710-0.983$ ), but costs in the prior year showed a positive association with pneumonia-specific readmission $(\mathrm{HR}=1.107,95 \%$ $\mathrm{CI}=1.015-1.206)$. LOS of the index hospitalization showed a positive association with pneumonia-specific, pneumonia-unrelated, and all-cause readmissions $(\mathrm{HR}=1.250,95 \% \mathrm{CI}=1.149-1.360 ; \mathrm{HR}=1.262,95 \%$ $\mathrm{CI}=1.162-1.370$, and $\mathrm{HR}=1.236,95 \% \mathrm{CI}=1.165-$ 1.311 , respectively). In addition, asthma showed associations with higher readmission for pneumonia-specific, pneumonia-unrelated, and all-cause readmissions $(\mathrm{HR}=1.211,95 \% \mathrm{CI}=1.041-1.432 ; \mathrm{HR}=1.252,95 \%$ $\mathrm{CI}=1.070-1.466$; and $\mathrm{HR}=1.222,95 \% \mathrm{CI}=1.093-$ 1.367, respectively). About $1.03 \%$ between-hospital variation was observed in this study, in explaining the association between the number of doctors and pneumonia readmission.

\section{Cox proportional hazard model for pneumonia-specific 30-day readmission associated with combined effects of number of doctors per bed and number of beds}

Figure 2 shows the results of a multivariate Cox proportional hazard model for pneumonia-specific 30-day readmission associated with the combined effect of the number of doctors per bed and number of beds. 
Table 1 Characteristics according to 30-day pneumonia-specific, pneumonia-unrelated, and 30-day all-cause readmission rates among inpatients with pneumonia in 2003-2013

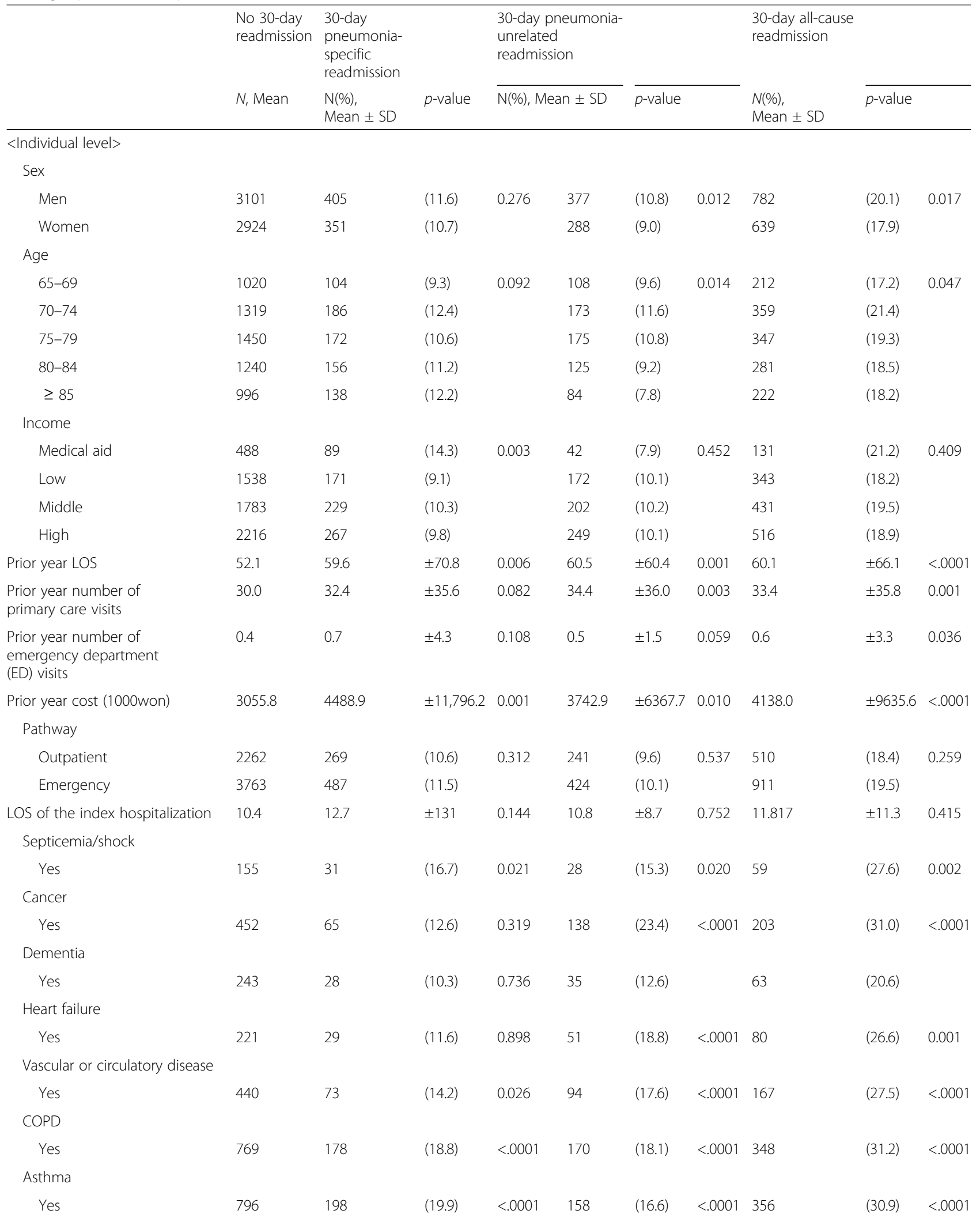


Table 1 Characteristics according to 30-day pneumonia-specific, pneumonia-unrelated, and 30-day all-cause readmission rates among inpatients with pneumonia in 2003-2013 (Continued)

\begin{tabular}{|c|c|c|c|c|c|c|c|c|c|c|}
\hline \multicolumn{11}{|l|}{ Renal failure } \\
\hline Yes & 182 & 28 & (13.3) & 0.363 & 40 & $(18.0)$ & $<.0001$ & 68 & $(27.2)$ & 0.001 \\
\hline \multicolumn{11}{|l|}{ Liver disease } \\
\hline Yes & 152 & 32 & (17.4) & 0.009 & 31 & $(16.9)$ & 0.002 & 63 & (29.3) & 0.000 \\
\hline \multicolumn{11}{|l|}{$<$ Hospital level $>$} \\
\hline \multicolumn{11}{|l|}{ Hospital classification } \\
\hline $\begin{array}{l}\text { Teaching hospital or general } \\
\text { hospital }\end{array}$ & 4331 & 498 & (10.3) & 0.001 & 500 & $(10.4)$ & 0.079 & 998 & (18.7) & 0.227 \\
\hline Hospital & 1694 & 258 & $(13.2)$ & & 165 & (8.9) & & 423 & (20.0) & \\
\hline \multicolumn{11}{|l|}{ Ownership } \\
\hline Public & 467 & 54 & (10.4) & 0.604 & 46 & $(9.0)$ & 0.490 & 100 & (17.6) & 0.392 \\
\hline Private & 5558 & 702 & $(11.2)$ & & 619 & $(10.0)$ & & 1321 & $(19.2)$ & \\
\hline \multicolumn{11}{|l|}{ Number of beds } \\
\hline Low & 1645 & 252 & (13.3) & $<.0001$ & 169 & $(9.3)$ & 0.054 & 421 & (20.4) & 0.116 \\
\hline Middle & 1747 & 245 & (12.3) & & 173 & $(9.0)$ & & 418 & (19.3) & \\
\hline High & 2633 & 259 & $(9.0)$ & & 323 & $(10.9)$ & & 582 & $(18.1)$ & \\
\hline \multicolumn{11}{|l|}{ Number of physicians per bed } \\
\hline Very low & 1232 & 188 & $(13.2)$ & $<.0001$ & 134 & (9.8) & 0.269 & 322 & (20.7) & 0.002 \\
\hline Low & 1960 & 307 & $(13.5)$ & & 205 & $(9.5)$ & & 512 & (20.7) & \\
\hline High & 1208 & 119 & $(9.0)$ & & 129 & (9.7) & & 248 & $(17.0)$ & \\
\hline Very high & 1625 & 142 & (8.0) & & 197 & $(10.8)$ & & 339 & $(17.3)$ & \\
\hline \multicolumn{11}{|l|}{ MRI } \\
\hline Yes & 5179 & 634 & $(10.9)$ & 0.134 & 579 & $(10.1)$ & 0.433 & 1213 & $(19.0)$ & 0.591 \\
\hline \multicolumn{11}{|l|}{ Year } \\
\hline 2003 & 189 & 12 & $(6.0)$ & 0.002 & 16 & $(7.8)$ & 0.355 & 28 & $(12.9)$ & 0.004 \\
\hline 2004 & 262 & 19 & (6.8) & & 32 & $(10.9)$ & & 51 & (16.3) & \\
\hline 2005 & 338 & 51 & (13.1) & & 32 & (8.7) & & 83 & (19.7) & \\
\hline 2006 & 393 & 33 & (7.8) & & 38 & (8.8) & & 71 & (15.3) & \\
\hline 2007 & 421 & 44 & (9.5) & & 46 & (9.9) & & 90 & (17.6) & \\
\hline 2008 & 471 & 69 & (12.8) & & 59 & $(11.1)$ & & 128 & (21.4) & \\
\hline 2009 & 526 & 57 & (9.8) & & 45 & (7.9) & & 102 & (16.2) & \\
\hline 2010 & 543 & 78 & (12.6) & & 68 & $(11.1)$ & & 146 & $(21.2)$ & \\
\hline 2011 & 855 & 120 & (12.3) & & 86 & (9.1) & & 206 & (19.4) & \\
\hline 2012 & 997 & 148 & (12.9) & & 130 & $(11.5)$ & & 278 & (21.8) & \\
\hline 2013 & 1030 & 125 & (10.8) & & 113 & (9.9) & & 238 & (18.8) & \\
\hline Total & 6025 & 756 & $(11.2)$ & & 665 & (9.9) & & 1421 & (19.1) & \\
\hline
\end{tabular}

Abbreviations: COPD chronic obstructive pulmonary disease, $E D$ emergency department, $L O S$ length of stay, MRI magnetic resonance imaging. Foot note: $\mathrm{n}(\%)$ for categorical variables; Mean \pm SD for continuous variables

Pneumonia-specific 30-day readmission was significantly higher for patients admitted to hospitals with fewer beds and doctors per bed than those admitted to better equipped and staffed hospitals ( $\mathrm{HR}=1.317,95 \%$ $\mathrm{CI}=1.008-1.722)$. In addition, hospitals with a moderate number of beds and a lower number of doctors per bed were associated with pneumonia-specific 30-day readmission $(\mathrm{HR}=1.243,95 \% \mathrm{CI}=1.013-1.526)$.

\section{Discussion}

This paper examined the effect of the number of doctors per bed on 30-day readmission, generally considered as 

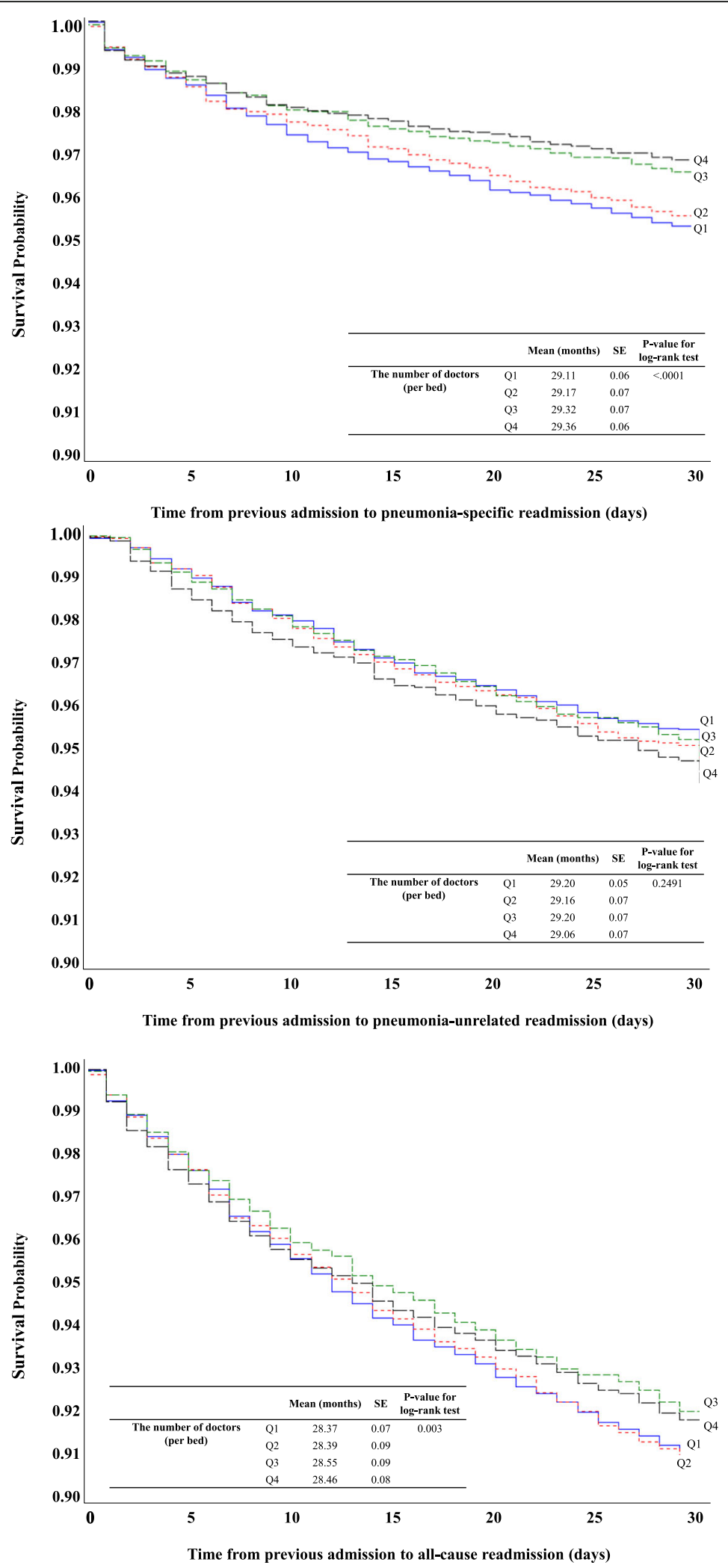

Fig. 1 Kaplan-Meier curves of all-cause 30-day readmissions according to the number of doctors per bed 
Table 2 Multivariate Cox proportional hazard models with 30-day pneumonia-specific, 30-day pneumonia-unrelated, and 30-day all-cause readmission rates for pneumonia in 2003-2013

\begin{tabular}{|c|c|c|c|c|c|c|c|c|c|}
\hline & \multicolumn{3}{|c|}{$\begin{array}{l}\text { 30-day pneumonia-specific } \\
\text { readmission }\end{array}$} & \multicolumn{3}{|c|}{$\begin{array}{l}\text { 30-day pneumonia-unrelated } \\
\text { readmission }\end{array}$} & \multicolumn{3}{|c|}{$\begin{array}{l}\text { 30-day all-cause } \\
\text { readmission }\end{array}$} \\
\hline & \multirow[t]{2}{*}{$\overline{H R}$} & \multicolumn{2}{|c|}{$95 \% \mathrm{Cl}$} & \multirow[t]{2}{*}{$\mathrm{HR}$} & \multicolumn{2}{|l|}{$95 \% \mathrm{Cl}$} & \multirow[t]{2}{*}{$\overline{H R}$} & \multicolumn{2}{|l|}{$95 \% \mathrm{Cl}$} \\
\hline \multicolumn{7}{|l|}{$\langle$ <ndividual level $>$} & & & \\
\hline \multicolumn{10}{|l|}{ Sex } \\
\hline Men & 1.000 & & & 1.000 & & & 1.000 & & \\
\hline Women & 1.010 & 0.875 & 1.166 & 1.072 & 0.930 & 1.235 & 1.040 & 0.940 & 1.150 \\
\hline \multicolumn{10}{|l|}{ Age } \\
\hline $65-69$ & 1.000 & & & 1.000 & & & 1.000 & & \\
\hline $70-74$ & 1.223 & 0.968 & 1.547 & 1.128 & 0.903 & 1.410 & 1.174 & 0.999 & 1.380 \\
\hline $75-79$ & 1.069 & 0.843 & 1.355 & 1.093 & 0.875 & 1.364 & 1.090 & 0.927 & 1.282 \\
\hline $80-84$ & 1.101 & 0.864 & 1.402 & 1.046 & 0.830 & 1.318 & 1.086 & 0.918 & 1.283 \\
\hline$\geq 85$ & 1.175 & 0.907 & 1.522 & 0.919 & 0.703 & 1.201 & 1.058 & 0.879 & 1.274 \\
\hline \multicolumn{10}{|l|}{ Income } \\
\hline Medical aid & 1.323 & 1.020 & 1.717 & 0.796 & 0.586 & 1.080 & 1.048 & 0.861 & 1.276 \\
\hline Low & 1.037 & 0.864 & 1.245 & 1.089 & 0.916 & 1.294 & 1.064 & 0.938 & 1.205 \\
\hline Middle & 1.031 & 0.868 & 1.223 & 0.965 & 0.817 & 1.141 & 0.993 & 0.881 & 1.118 \\
\hline High & 1.000 & & & 1.000 & & & 1.000 & & \\
\hline Prior year LOS & 0.836 & 0.710 & 0.983 & 1.181 & 1.001 & 1.393 & 0.997 & 0.888 & 1.120 \\
\hline Prior year number of primary care visits & 0.919 & 0.823 & 1.027 & 0.945 & 0.846 & 1.056 & 0.929 & 0.859 & 1.005 \\
\hline Prior year number of emergency department (ED) visits & 1.008 & 0.990 & 1.025 & 0.995 & 0.965 & 1.025 & 1.003 & 0.988 & 1.019 \\
\hline Prior year cost (1000won) & 1.107 & 1.015 & 1.206 & 0.904 & 0.828 & 0.986 & 1.001 & 0.942 & 1.064 \\
\hline \multicolumn{10}{|l|}{ Pathway } \\
\hline Outpatient & 1.000 & & & 1.000 & & & 1.000 & & \\
\hline Emergency & 1.113 & 0.959 & 1.291 & 1.002 & 0.866 & 1.161 & 1.053 & 0.949 & 1.168 \\
\hline LOS of the index hospitalization & 1.250 & 1.149 & 1.360 & 1.262 & 1.162 & 1.370 & 1.236 & 1.165 & 1.311 \\
\hline \multicolumn{10}{|l|}{ Septicemia/shock } \\
\hline No & 1.000 & & & 1.000 & & & 1.000 & & \\
\hline Yes & 1.177 & 0.846 & 1.638 & 1.298 & 0.931 & 1.810 & 1.223 & 0.968 & 1.545 \\
\hline \multicolumn{10}{|l|}{ Cancer } \\
\hline No & 1.000 & & & 1.000 & & & 1.000 & & \\
\hline Yes & 0.540 & 0.424 & 0.687 & 1.212 & 1.015 & 1.447 & 0.877 & 0.762 & 1.009 \\
\hline \multicolumn{10}{|l|}{ Dementia } \\
\hline No & 1.000 & & & 1.000 & & & 1.000 & & \\
\hline Yes & 0.605 & 0.414 & 0.885 & 1.126 & 0.832 & 1.526 & 0.837 & 0.660 & 1.062 \\
\hline \multicolumn{10}{|l|}{ heart failure } \\
\hline No & 1.000 & & & 1.000 & & & 1.000 & & \\
\hline Yes & 0.695 & 0.492 & 0.980 & 1.181 & 0.904 & 1.544 & 0.930 & 0.754 & 1.148 \\
\hline \multicolumn{10}{|l|}{ Vascular or circulatory disease } \\
\hline No & 1.000 & & & 1.000 & & & 1.000 & & \\
\hline Yes & 0.749 & 0.584 & 0.961 & 1.155 & 0.938 & 1.422 & 0.968 & 0.826 & 1.134 \\
\hline \multicolumn{10}{|l|}{ COPD } \\
\hline No & 1.000 & & & 1.000 & & & 1.000 & & \\
\hline Yes & 0.897 & 0.760 & 1.059 & 1.171 & 1.003 & 1.367 & 1.029 & 0.919 & 1.152 \\
\hline
\end{tabular}


Table 2 Multivariate Cox proportional hazard models with 30-day pneumonia-specific, 30-day pneumonia-unrelated, and 30-day all-cause readmission rates for pneumonia in 2003-2013 (Continued)

\begin{tabular}{|c|c|c|c|c|c|c|c|c|c|}
\hline \multicolumn{10}{|l|}{ Asthma } \\
\hline No & 1.000 & & & 1.000 & & & 1.000 & & \\
\hline Yes & 1.221 & 1.041 & 1.432 & 1.252 & 1.070 & 1.466 & 1.222 & 1.093 & 1.367 \\
\hline \multicolumn{10}{|l|}{ Renal failure } \\
\hline No & 1.000 & & & 1.000 & & & 1.000 & & \\
\hline Yes & 0.842 & 0.600 & 1.182 & 1.122 & 0.840 & 1.500 & 0.977 & 0.784 & 1.217 \\
\hline \multicolumn{10}{|l|}{ Liver disease } \\
\hline No & 1.000 & & & 1.000 & & & 1.000 & & \\
\hline Yes & 0.848 & 0.592 & 1.214 & 1.155 & 0.845 & 1.577 & 0.993 & 0.785 & 1.257 \\
\hline \multicolumn{10}{|l|}{$<$ Hospital level $>$} \\
\hline \multicolumn{10}{|l|}{ Hospital classification } \\
\hline Teaching hospital or general hospital & 1.000 & & & 1.000 & & & 1.000 & & \\
\hline Hospital & 1.078 & 0.845 & 1.373 & 0.929 & 0.706 & 1.223 & 1.005 & 0.839 & 1.205 \\
\hline \multicolumn{10}{|l|}{ Ownership } \\
\hline Public & 1.000 & & & 1.000 & & & 1.000 & & \\
\hline Private & 1.201 & 0.906 & 1.591 & 1.144 & 0.851 & 1.536 & 1.169 & 0.955 & 1.431 \\
\hline \multicolumn{10}{|l|}{ The number of beds } \\
\hline Low & 1.043 & 0.779 & 1.395 & 0.802 & 0.591 & 1.088 & 0.901 & 0.732 & 1.109 \\
\hline Middle & 0.945 & 0.746 & 1.198 & 0.754 & 0.597 & 0.953 & 0.835 & 0.708 & 0.984 \\
\hline High & 1.000 & & & 1.000 & & & 1.000 & & \\
\hline \multicolumn{10}{|l|}{ The number of doctors per bed } \\
\hline Q1 & 1.334 & 0.976 & 1.823 & 1.217 & 0.888 & 1.669 & 1.276 & 1.026 & 1.587 \\
\hline Q2 & 1.406 & 1.072 & 1.843 & 1.168 & 0.898 & 1.519 & 1.280 & 1.064 & 1.540 \\
\hline Q3 & 1.009 & 0.789 & 1.290 & 1.036 & 0.829 & 1.295 & 1.033 & 0.878 & 1.215 \\
\hline Q4 & 1.000 & & & 1.000 & & & 1.000 & & \\
\hline \multicolumn{10}{|l|}{ MRI } \\
\hline No & 1.000 & & & 1.000 & & & 1.000 & & \\
\hline Yes & 1.182 & 0.935 & 1.495 & 1.154 & 0.883 & 1.508 & 1.157 & 0.971 & 1.379 \\
\hline \multicolumn{10}{|l|}{ Year } \\
\hline 2003 & 1.000 & & & 1.000 & & & 1.000 & & \\
\hline 2004 & 1.065 & 0.563 & 2.014 & 1.318 & 0.759 & 2.289 & 1.234 & 0.813 & 1.875 \\
\hline 2005 & 1.544 & 0.885 & 2.694 & 1.115 & 0.653 & 1.905 & 1.352 & 0.919 & 1.990 \\
\hline 2006 & 1.065 & 0.563 & 2.014 & 0.874 & 0.508 & 1.505 & 0.863 & 0.575 & 1.294 \\
\hline 2007 & 1.544 & 0.885 & 2.694 & 1.043 & 0.622 & 1.749 & 1.027 & 0.699 & 1.510 \\
\hline 2008 & 1.065 & 0.563 & 2.014 & 1.181 & 0.715 & 1.950 & 1.203 & 0.829 & 1.744 \\
\hline 2009 & 1.544 & 0.885 & 2.694 & 0.895 & 0.534 & 1.500 & 0.943 & 0.644 & 1.380 \\
\hline 2010 & 1.065 & 0.563 & 2.014 & 1.043 & 0.634 & 1.716 & 1.085 & 0.751 & 1.568 \\
\hline 2011 & 1.544 & 0.885 & 2.694 & 0.938 & 0.566 & 1.552 & 1.000 & 0.691 & 1.447 \\
\hline 2012 & 1.065 & 0.563 & 2.014 & 1.197 & 0.736 & 1.948 & 1.182 & 0.825 & 1.693 \\
\hline 2013 & 1.544 & 0.885 & 2.694 & 1.125 & 0.689 & 1.838 & 1.032 & 0.717 & 1.484 \\
\hline
\end{tabular}

Abbreviations: COPD chronic obstructive pulmonary disease, ED emergency department, LOS length of stay, MRI magnetic resonance imaging.

an indicator of quality of care, particularly when patients are readmitted for the same condition due to treatment failure [19].
In this study, of the 7446 patients admitted for pneumonia, $19.1 \%$ were readmitted to the hospital within 30 days, and the pneumonia-specific readmission was 


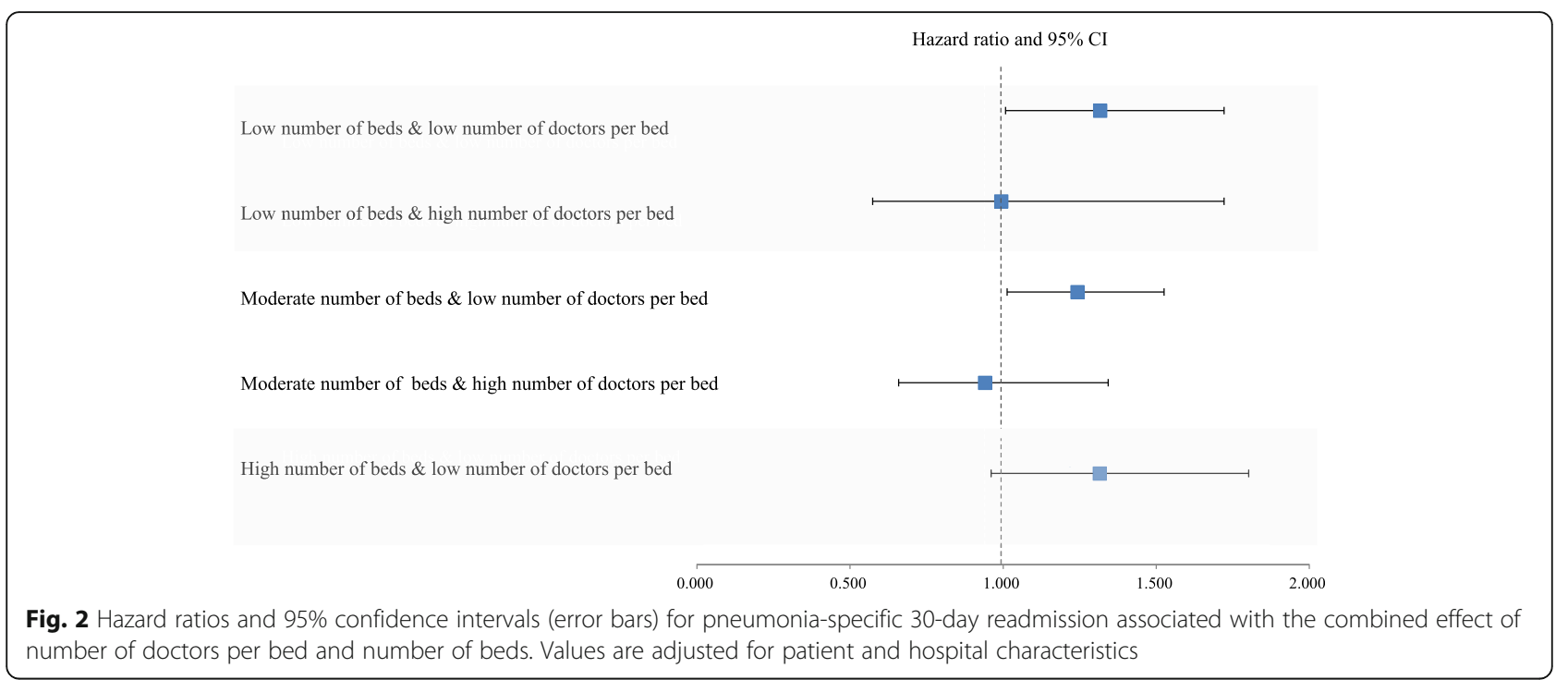

$53.2 \%$. In the U.S., the proportion of patients readmitted after pneumonia hospitalization within 30 days was $18.3 \%$ and readmission for the same condition was $22.4 \%$ [16]. The corresponding values in a study conducted in northern Spain were $7.3 \%$ and 35.8\% [19]. Similarly, the 90 -day readmission rate was $11.2 \%$ in Canada [21]. Compared to our data, pneumonia readmission within 30 days of discharge was on the high side in South Korea, and pneumonia-specific readmission was considerably higher than that of other countries.

We found that patients with pneumonia treated in hospitals with a higher number of doctors per bed were less likely to be readmitted. In addition, risk factors of pneumonia-specific readmission were different from those of pneumonia-unrelated readmission. Of interest, pneumonia-specific 30-day readmission showed significant relationships with the combined effect of number of doctors per bed and number of beds. Pneumonia patients admitted to hospitals with a smaller number of beds and a smaller number of doctors were more likely to be rehospitalized for the same condition. The 30-day pneumonia-specific readmission rate for patients admitted with pneumonia was explained better by the combined effect of physician and bed volumes than the number of doctors per bed alone.

It is unclear why a lower doctor staffing level is related to higher readmission rates. Fewer doctors may not be able to provide care for patients requiring additional attention by medical professionals. Alternatively, a lower number of doctors per bed may make it difficult to treat the complex medical conditions related to pneumonia.

The findings of this study are similar to those of previous investigations which showed that better outcome was associated with higher doctor staffing levels [22-24]. In case of socioeconomic status (SES) factors such as income, there are arguments about SES and readmission, although CMS does not adjust for SES when calculating readmission [25]. The findings of the current study that readmission was not related to income level was similar to those of other studies. However, in South Korea, pneumonia readmission rates were publicly reported for quality evaluation starting from 2015 [26]. Therefore, more studies about risk factors for pneumonia readmission are required to improve healthcare quality in Korea. Understanding the association between the number of doctors per bed and hospital readmission for pneumonia can provide insights into which hospitals are likely to show high readmission rates and how to prevent this outcome.

There are several limitations in this study. First, this study could not consider illness severity due to data limitation. An inaccurate severity control could act as a source of bias because severe patients tend to be admitted to tertiary or large hospitals. Second, we were unable to classify doctors by job specification because the data used in this study lacked information on the type of doctor. Third, although we used cohort data, we urge caution in interpreting the study results. This study demonstrated an association between the number of doctors per bed and readmission. However, this result does not prove causality. Fourth, because this study only included patients aged 65 years or older, results may differ from patients younger than 65 years of age. As pneumonia characteristics are very different between the elderly and the young, patients under 65 years of age were not included in this analysis.

Despite these limitations, this study has several strengths. First, we used national cohort sample data on health insurance claims, which includes patient demographic and socioeconomic data, medical history, and hospital information for about 1 million people. This representative nationwide sample ensured high external 
validity. Second, we adjusted for both patient- and hospital-level factors because both types affect readmission and ultimately, patient outcome. To our knowledge, most studies on 30-day readmission have focused on patient demographic and disease-specific factors. Third, we tried to design homogeneous groups and to focus on readmission due to in-hospital treatment failure by excluding readmission for other health problems in the subgroup analysis. Fourth, this paper provides valuable information for policy makers in managing readmission and improving quality of care. As hospital readmission rates can differ according to the number of doctors per bed, implementation of different types of strategies is required depending on the number of doctors in a specific hospital. Fifth, this study attempted to focus on unplanned and avoidable readmissions to assess quality of care and we only included readmissions for pneumonia to the same hospital.

\section{Conclusion}

In summary, our results show that patients with pneumonia cared for by a higher volume of doctors were less likely to be readmitted. Notably, the pneumonia-specific 30-day readmission was significantly associated with the combined effect of physician and hospital bed volumes. Recently, Korea has focused on increasing National Health Insurance coverage and reducing medical costs. In the coming decades, Korea should focus on improving the quality of care [27]. The findings described here suggest that policy makers should continue to monitor readmission rates and select hospitals with a low number of doctors per bed to ensure quality improvement, particularly among hospitals with few doctors and many beds.

\begin{abstract}
Abbreviations
AMI: Acute myocardial infarction; CCl: Charlson comorbidity index; CMS: Centers for Medicare \& Medicaid Services; COPD: Chronic Obstructive Pulmonary Disease; LOS: Length of stay; MRI: Magnetic resonance imaging; NHIS: National Health Insurance Service; OECD: Organization for Economic Cooperation and Development; SES: Socioeconomic status
\end{abstract}

\section{Acknowledgements}

National Health Insurance Service provided national level of data.

\section{Funding}

This research received no specific grant from any funding agency in the public, commercial or not-for-profit sectors.

\section{Availability of data and materials}

The data supporting this article is available in https://nhiss.nhis.or.kr/bd/ab/ bdaba021eng.do, after the NHIS's committee evaluation and payment of fee.

\section{Authors' contributions}

JEL designed the study, carried out the statistical analysis, and wrote the paper. THK, KHC and KTH provided important comments for the method and discussion. E-CP directed this study as corresponding author. All authors read and approved the final manuscript.

\section{Competing interests}

The authors declare that they have no competing interests.
Consent for publication

Not applicable.

Ethics approval and consent to participate

IRB of Graduate School of Public Health in Yonsei University.

\section{Publisher's Note}

Springer Nature remains neutral with regard to jurisdictional claims in published maps and institutional affiliations.

\section{Author details}

${ }^{1}$ Department of Public Health, Yonsei University College of Medicine, Seoul, Republic of Korea. ${ }^{2}$ Institute of Health Services Research, Yonsei University College of Medicine, Seoul, Republic of Korea. ${ }^{3}$ Department of Hospital Administration, Graduate School of Public Health, Yonsei University, Seoul, Republic of Korea. ${ }^{4}$ Department of Preventive Medicine, Yonsei University College of Medicine, 50 Yonsei-ro, Seodaemun-gu, Seoul 120-752, Republic of Korea.

Received: 29 April 2016 Accepted: 2 June 2017

Published online: 08 June 2017

\section{References}

1. Jung K-S. Pneumonia in the elderly patients. Korean J Med. 2008;75(2):129-40.

2. Statistics Korea. 2013. Available from: http://kosis.kr/statisticsList/statisticsList_ 01List.jsp?wwcd=MT_ZTITLE\&parentld=A\#SubCont. Accessed 5 Mar 2016.

3. Yoon HK. Changes in the epidemiology and burden of community-acquired pneumonia in Korea. Korean J Intern Med. 2014;29(6):735-7.

4. Metersky ML, Tate JP, Fine MJ, Petrillo MK, Meehan TP. Temporal trends in outcomes of older patients with pneumonia. Arch Intern Med. 2000;160(22):3385-91.

5. Baker DW, Einstadter D, Husak SS, Cebul RD. Trends in postdischarge mortality and readmissions: has length of stay declined too far? Arch Intern Med. 2004;164(5):538-44

6. Steel K, Gertman PM, Crescenzi C, Anderson J. latrogenic illness on a general medical service at a university hospital. N Engl J Med. 1981;304(11):638-42.

7. Westert GP, Lagoe RJ, Keskimaki I, Leyland A, Murphy M. An international study of hospital readmissions and related utilization in Europe and the USA. Health Policy (New York). 2002;61(3):269-78.

8. Lee EW. Selecting the best prediction model for readmission. J Prev Med Public Health. 2012;45(4):259-66.

9. Lindenauer PK, Bernheim SM, Grady JN, Lin Z, Wang Y, Wang Y, et al. The performance of US hospitals as reflected in risk-standardized 30-day mortality and readmission rates for medicare beneficiaries with pneumonia. J Hosp Med. 2010;5(6):E12-8.

10. Van Walraven C, Jennings A, Forster AJ. A meta-analysis of hospital 30-day avoidable readmission rates. J Eval Clin Pract. 2012;18(6):1211-8.

11. Ministry of Health \& Welfare. Guidelines for hospital evaluation program 2009. 2009.

12. Kocher RP, Adashi EY. Hospital readmissions and the Affordable Care Act: paying for coordinated quality care. JAMA. 2011;306(16):1794-5.

13. Chen $Y$, Stewart P, Dales R, Johansen H, Scott G, Taylor G. Ecological measures of socioeconomic status and hospital readmissions for asthma among Canadian adults. Respir Med. 2004;98(5):446-53.

14. Kim SJ, Han K-T, Lee HJ, Kwon JA, Park E-C. Positive effects of medical staffing on readmission within 30 days after discharge: a retrospective analysis of obstetrics and gynecology data. The European Journal of Public Health. 2016;26(6):935-9.

15. Organization for Economic Cooperation and Development. Health at a glance 2015. 2015.

16. Dharmarajan K, Hsieh AF, Lin Z, Bueno H, Ross JS, Horwitz LI, et al. Diagnoses and timing of 30-day readmissions after hospitalization for heart failure, acute myocardial infarction, or pneumonia. JAMA. 2013;309(4):355-63.

17. Shulan M, Gao K, Moore CD. Predicting 30-day all-cause hospital readmissions. Health Care Manag Sci. 2013;16(2):167-75.

18. Shorr AF, Zilberberg MD, Reichley R, Kan J, Hoban A, Hoffman J, et al. Readmission following hospitalization for pneumonia: the impact of pneumonia type and its implication for hospitals. Clin Infect Dis. 2013;57(3):362-7. 
19. Capelastegui A, Espana Yandiola PP, Quintana JM, Bilbao A, Diez R, Pascual S, et al. Predictors of short-term rehospitalization following discharge of patients hospitalized with community-acquired pneumonia. Chest. 2009;136(4):1079-85.

20. Hyder O, Dodson RM, Nathan H, Schneider EB, Weiss MJ, Cameron JL, et al. Influence of patient, physician, and hospital factors on 30-day readmission following pancreatoduodenectomy in the United States. JAMA Surg. 2013;148(12):1095-102.

21. Neupane B, Walter SD, Krueger P, Marrie T, Loeb M. Predictors of inhospital mortality and re-hospitalization in older adults with community-acquired pneumonia: a prospective cohort study. BMC Geriatr. 2010;10(1):22.

22. Han K-T, Park E-C, Kim SJ, Kim W, Hahm M-I, Jang S-I, et al. Effective strategy for improving health care outcomes: Multidisciplinary care in cerebral infarction patients. Health Policy (New York). 2015;119(8):1039-45.

23. Han K-T, Kim SJ, Jang S-I, Hahm M-I, Kim SJ, Lee SY, et al. The outcomes of psychiatric inpatients by proportion of experienced psychiatrists and nurse staffing in hospital: New findings on improving the quality of mental health care in South Korea. Psychiatry Res. 2015;229(3):880-6.

24. Kim SJ, Park E-C, Kim SJ, Han K-T, Han E, Jang S-I, et al. The effect of competition on the relationship between the introduction of the DRG system and quality of care in Korea. The European Journal of Public Health. 2016;26(1):42-7.

25. Glance LG, Kellermann AL, Osler TM, Li Y, Li W, Dick AW. Impact of risk adjustment for socioeconomic status on risk-adjusted surgical readmission rates. Ann Surg. 2016;263(4):698-704.

26. Health Insurance Review \& Assessment Service (HIRA). 2015 1st Pneumonia Quality Assessment. 2016.

27. OECD. OECD health care quality review. Paris: Organisation for Economic Cooperation and Development; 2012.

\section{Submit your next manuscript to BioMed Central and we will help you at every step:}

- We accept pre-submission inquiries

- Our selector tool helps you to find the most relevant journal

- We provide round the clock customer support

- Convenient online submission

- Thorough peer review

- Inclusion in PubMed and all major indexing services

- Maximum visibility for your research

Submit your manuscript at www.biomedcentral.com/submit 